\title{
Characteristics of Chewing: An Update of the Literature
}

\author{
Características de la Masticación: Una Actualización de la Literatura
}

\author{
Ramón Fuentes ${ }^{1,2}$; Constanza Farfán ${ }^{1,2,3}$ \& Alain Arias ${ }^{1,2,3}$
}

\begin{abstract}
FUENTES, R.; FARFÁN, C. \& ARIAS, A. Characteristics of chewing: An update of the literature. Int. J. Odontostomat., 15(4):873-881, 2021.

ABSTRACT: Chewing is the first step in the digestion process in mammals. It is a highly coordinated process with a complex sensorimotor activity, the aim of which is to prepare foods for the formation of the alimentary bolus and then swallowing. It is a process with defined stages and patterns of movement that adapt to changes derived from the environment or the individual. Here, we review the main characteristics of chewing, including aspects of the physiology and characteristics of the mechanics of mandibular movement. We highlight the latest advances reported and the new methodologies used for a chewing analysis, which has made it possible to collect more precise and reliable data. Thus, we will see how the new technologies have provided a better understanding of this function and its relation to aspects of an individual's general health such as nutrition or the appearance of neurodegenerative diseases. Also, in this review we emphasize the close relation that exists between chewing and a person's quality of life.
\end{abstract} of life.

KEY WORDS: chewing, chewing cycles, mandibular movement, nutrition, neurodegenerative diseases, quality

\section{INTRODUCTION}

Chewing is the first and most important step in the digestion process in most mammals. It is characterized by a complex sensorimotor activity that consists of rhythmic movements of opening and closing of the jaw, the objective of which is to reduce, grind and moisten foods for the formation of the bolus that can be swallowed and the digestion process continued (Lund, 1991; Cho et al., 2015; Isabel et al., 2015; Iguchi et al., 2015).

Chewing is a conditioned process that depends on the position, morphology and presence of the teeth in the mandible and maxilla. It is a learned and semiautomatic process that occurs after the teeth have erupted and that is gradually assimilated by the nervous system, becoming a highly stereotyped event but one dependent on neurosensory feedback (Dellow \& Lund, 1971). The development of mastication patterns is related to the eruption of the first teeth, those that will give the sense of mandibular position to the baby, a previously nonexistent condition due to the lack of these structures. This leads to the development of the first dental contacts, causing in turn the first mandibular movements with little coordination. As time passes, the first masticatory reflexes will be conditioned and perfected with the appearance of proprioception (periodontal, articular, of the tongue and the mucosa), which will ultimately make it possible to develop a mature masticatory movement with maximum functionality and efficiency.

In addition to being a semiautomatic process, chewing is a highly coordinated event. This coordination prevents any type of damage to the components of the system in which strong forces intervene as the result of the action of the masticatory muscles. This complex motor activity is based on conditioned reflexes closely related to occlusion, the periodontium, temporomandibular joints (TMJs), masticatory muscles, palate and salivary glands (Soboleva et al.,2005).

\footnotetext{
${ }^{1}$ Department of Integral Adult Dentistry, Dental School, Universidad de La Frontera, Temuco, Chile.

${ }^{2}$ Research Centre in Dental Sciences (CICO), Dental School, Universidad de La Frontera, Temuco, Chile.

${ }^{3}$ Universidad Adventista de Chile, Chillán, Chile.
} 
In chewing, it is also possible to distinguish different types of movement patterns, which are closely related to type of food being chewed. For example, when chewing hard food, the lateral movements of the jaw predominate, whereas with soft food chewing uses vertical movements of opening and closing. In addition, it is important to consider that chewing can influence and modulate several other physiological processes related to human nutrition. For example, during mastication the salivary glands are stimulated to produce saliva and enable the formation of the bolus that will then be swallowed. On the other hand, it has been seen that the choice of certain foods to be included in the diet is strongly related to a person's chewing ability or efficiency (Mobley \& Dounis, 2013), which will also depend on the state of the teeth (Ellis et al., 2008).

\section{PHASES OF MASTICATION}

Different phases are distinguished in the mastication process, where there is a narrow coordination and rhythm among the teeth, masticatory muscles, tongue, lips and cheeks. This coordination of movement depends on a central pattern generator located in the brain stem (Lund \& Kolta, 2006). Through the different phases of mastication, it is possible to gain a degree of crushing of the particles that is optimal and that allows the formation of the bolus. Between each of these phases there are predominant movements of the jaw that are then mixed when passing from one stage to the next.

The first "incision phase" begins with the incisors. In this phase a shearing motion is described where the upper incisors work as an upper shear cutter while the lower incisors act as a lower shear cutter. When the incision occurs, at the same time an advancement of the mandible occurs that is usually identified as a preparatory movement. This movement occurs thanks to the contraction of the lateral pterygoid, suprahyoid and digastric muscles, when taking the food towards the mouth. With the help of the tongue, the food is positioned for the cutting movement, making the incision protrusive (simultaneous contraction of the lateral pterygoids) or lateral protrusive (unequal contraction of the pterygoids). The incision of foods and the contraction of the masticatory muscles will depend on the state of the person's teeth and the balance of their occlusion. In the case of more fibrous foods, such as meat, it is necessary to "tear" the food by having the canines apply greater cutting force.
After cutting the foods, next comes the "crushing phase", which occurs in the region of the premolars. In this phase there is a combination of the movements from the previous phase with lateral rotation movements that enable discussion of the posterior teeth finally giving rise to several masticatory strokes or cycles. In this phase the food is prepared to pass to the region of the molars and continue with the "grinding phase". In this last phase the food is reduced to fine particles, finally allowing the formation and swallowing of the bolus.

A current model describes this process as "ingestion", which begins with the selection of a food and ends with its passage through the upper esophageal sphincter during "swallowing". It is considered that ingestion is controlled at three checkpoints, each of which can discontinue ingestion. The first checkpoint is the voluntary selection of food. The second checkpoint consists of the sensory signals of the food, which is obtained after the incisors transport the food to the molars. During this phase, each mouthful is analyzed for taste, retronasal olfaction and oral receptors of the somatosensory system. If this phase is successfully completed, then the food is transformed into a bolus crushing and grinding the foods and the central pattern generators of mastication located in the cerebral cortex and brain stem are activated and the physiological responses needed to prepare the digestion of foods are anticipated. The third checkpoint is swallowing, with the opening of the upper esophageal sphincter (Bourdiol et al., 2020).

\section{COMPLEX MOTOR ACTIVITY}

Chewing is based on conditioned reflexes, which are closely related to occlusion, the periodontium, masticatory muscles and TMJs. Chewing is a function guided by basic reflexes such as the jaw opening reflex, the jaw closing reflex and the myotatic (stretch) reflex (Avivi-Arber \& Sessle, 2018). The basic pattern of rhythmic movements of the jaw produced during chewing is generated by a neural network located in the brain stem and that is referred to as the masticatory central pattern generator (Morquette et al., 2012). This network is composed mainly of neurons associated with the trigeminal system and is found between the anterior edge of the trigeminal motor nucleus and facial nucleus. Its function is related to the generation of rhythmic patterns as a motor response even in the absence of ascending (peripheral) or descending stimuli. The neurons of the masticatory central pattern generator are subjected to feedback mechanisms that emanate 
from various peripheral receptors located in the stomatognathic system and from many central areas such as the cerebral cortex (tonsil, hypothalamus, cerebellum, etc.),thereby causing changes in the motor rhythm of mastication and variability between each masticatory cycle (Aguirre-Siancas, 2017).

\section{JAW MOVEMENT PATTERNS}

Jaw movements during chewing are complex and can be described in three spatial planes (frontal, sagittal and horizontal). These movements can be opening or closing, right or left laterality and protrusive or retrusive. It has been shown that the masticatory cycles evaluated through the area have variations during the course of the mastication process, showing a tendency to be of greater amplitude at the beginning of the masticatory process, to then decrease and remain in a "stable" area (Fuentes et al., 2017). As the oral cavity opens wider, the masticatory movements in the horizontal plane are smaller, i.e., the masticatory cycle at the outset should be narrower laterally. However, an analysis with 3D high-resolution images revealed a great variation in amplitude of each masticatory cycle in the three spatial planes (Fig.1).

Chewing patterns can be divided into four types: alternate bilateral chewing, simultaneous bilateral chewing, preferential unilateral chewing and chronic unilateral chewing (Genaro et al., 2009; Brizuela Cordero et al., 2011). It has been described that the most physiological chewing pattern is the alternate bilateral, where the parotic and submaxillary glands are stimulated by the action of the masseter muscles. In addition, in this pattern, support structures of the tooth are stimulated, occlusal stability is promoted, bilateral muscle patterns and dental hygiene is facilitated (Brizuela Cordero et al.). It has been reported that this type of chewing is most frequent in the young adult dentate population (Van der Laan, 1998; Moya et al., 2017). On the other hand, unilateral chewing involves the presence of asymmetries in masticatory dynamics and differences in the load distribution in joints and muscles (Jiménez et al., 2016). In subjects with the loss of posterior teeth, a protrusive masticatory pattern has been described, where foods are crushed with the anterior teeth, due to the absence of the posterior ones.

CHEWING ADAPTATION. Chewing can adapt to several types of changes derived from the environment or the individual. For example, it has been described that the masticatory cycles vary to adapt to the types of foods, that chewing is subjected to a slow reprogramming to adapt to evolutionary conditions such as orthodontic movements, dental wear and tear or aging and that it must also adapt to discontinuities such as tooth loss or prosthodontic occlusal rehabilitation, even dental pain, or mucosa or TMJ pain (Bourdiol et al.).

\section{Type of food}

Chewing adapts to the characteristics of the chewed food (Van der Bilt, 1995). The analysis of chewing and its adaptation to different foods has been very complex, since many of its characteristics (for example, texture, flavor, size, shape) can have a simultaneous effect. Consequently, only the mechanical properties of the food have been considered for the analyses described. This is one of the reasons why the hardness of the food has been the most studied characteristic or property (Woda et al., 2006).

To study chewing, different food types have been used for testing, including synthetic foods made from elastomers that allow the physical properties of shape and size to be controlled, but they cannot be ingested (Nicolas et al., 2007). Foods of natural origin have also been used, such as almonds, carrots and peanut, which allows the study subjects to chew more naturally and comfortably (Yoshida et al., 2009). It should also be mentioned that these studies also use cereals like granola (Fueki et al., 2013).

Aging is a dynamic process, where various physiological changes occur; in the oral cavity tooth loss is one of the most common alterations (Saez Carriera et al., 2007). The most popular rehabilitative treatment of people with tooth loss is fully and partially removable prostheses. It has been described that these can modify the chewing process by presenting horizontal and/or vertical oscillating movements during the function, which causes unilateral mastication (Rosado De Oliveira et al., 2005). This modification of the masticatory function leads to a change in the manner of eating, with softer foods being chosen (Bourdiol et al.). Current studies have used peanut as the soft food prototype to analyze the characteristics of chewing, and it has been reported that subjects rehabilitated with implant-supported protheses demonstrate chewing characteristics similar to dentate subjects (Rivera et al., 2020), in addition to the greater force and increased contact area, offering greater comfort and improving the chewing process compared to the conventional prothesis (Ohkubo et al., 2008). 
This may be due to the greater retention, support and prosthetic stability in this group (Lauzardo et al., 2013). Another food that has been analyzed and its results compared with peanut is cereal-based granola. With a size similar to the peanut, it has been reported that subjects with removable protheses execute wider masticatory movements when chewing granola, and higher values are generally reported for variables such as frequency, speed and area of masticatory cycles compared to the peanut, which is recognized as a food that stimulates chewing and therefore is highly recommended from a mechanical point of view for those subjects who have dental prostheses and who have seen their movements reduced as they lose teeth (Farfán et al., 2020).

\section{MASTICATORY CYCLES}

Phases: The masticatory cycle is the basic functional unit of chewing and is comprised of three phases: opening, where there is an isotonic contraction of the depressor muscles of the jaw; closing, where the jaw is elevated by action of the elevator muscles; and an occlusal phase, where the contact of the maxillary and mandibular teeth is produced by the isometric contraction of muscles (also described as masticatory stroke) (Brizuela Cordero et al.). The opening and closing phases can also be subdivided into slow and fast opening phases and slow and fast closing phases (Cho et al.). On the other hand, the mastication sequence can be divided into three stages: early, medium and delayed, in which the characteristics of the masticatory cycles change gradually (Iguchi et al.).

Number of masticatory cycles: Masticatory kinematics have been studied in subjects with different characteristics, such as fully dentate individuals, with class I molar or those with dental prostheses, with values being defined between 9 and 24 masticatory cycles and it being necessary to swallow $3.5 \mathrm{~g}$ of peanut (Fuentes et al., 2017). Other studies describe the number of masticatory strokes as increasing in subjects with dental prostheses, reaching 67 and 90 cycles in subjects with completely removable protheses, between 30 and 104 cycles in subjects with partially removable protheses and between 42 and 114 cycles in subjects with implant-supported protheses, all evaluated under similar conditions (Rivera et al.). This increase in the number of masticatory cycles could be because of the low or no peripheral sensitivity that these people have due to the progressive loss of the periodontal mechanoreceptors (Woda et al.).
Area of masticatory cycles: In recent decades, it has been possible to accurately determine the area of the masticatory cycles due to technological advances. Previous studies have only been able to describe this area in the frontal and sagittal planes (Gonçalves et al., 2014), whereas more recent studies with highresolution methods and accuracy have enabled the study in the horizontal plane (Fuentes et al., 2018a) (Farfán et al.). Thus, an average frontal area of 32.46 $\pm 25.02 \mathrm{~mm}^{2}$ and a sagittal area of $8.3 \pm 7.24 \mathrm{~mm}^{2}$ has been estimated in subjects with class I normal occlusion (Fuentes et al., 2018b). For subjects with removable prostheses, an area in the frontal plane has been described that varies from $39.22 \pm 4.07 \mathrm{~mm}^{2}$ (Rivera et al.) to $58.5 \pm 32.5 \mathrm{~mm}^{2}$ (Gonçalves et al.) and an area in the sagittal plane that varies from $10.90 \pm 5.82$ $\mathrm{mm} 2$ (Rivera et al.) to $12.5 \pm 2.5 \mathrm{~mm}^{2}$ (Gonçalves et al.). In the case of subjects with skeletal class III, average areas in the frontal plane of $63.5 \pm 45.7 \mathrm{~mm}^{2}$, in the sagittal plane of $19.3 \pm 13.4 \mathrm{~mm}^{2}$ and in the horizontal plane of $20.47 \pm 16.68 \mathrm{~mm}^{2}$ have been described (Fuentes et al., 2018a). There is wide variability in the amplitude of the masticatory cycles depending on the condition of the subject; these characteristics must be considered for the comprehensive assessment of chewing and clinical decision-making.

CHEWING ANALYSIS METHODS. Chewing has been evaluated using electromyography, kinematics, force sensors and videos (Nicolas et al.; Fuentes et al., 2017; Gonçalves et al.). Therefore, muscle strength, amplitude and trajectory, time and frequency of mastication cycles can be analyzed.

For the description and analysis of the kinematics of the masticatory cycles, several techniques have been used which offer differing degrees of precision and reliability. The classic studies have described chewing in two dimensions (sagittal and frontal plane) using such techniques as kinesiography (Toman et al., 2012), the ARCUSdigma system (Flores-Orozco et al., 2016) or the gnathohexograph (Kuninori et al., 2014; Yoshida et al., 2007). With the development of more modern electronic systems it has been possible to reach new levels of precision and reproducibility. This is the case for electromagnetic articulography (EMA), which is based on the use of alternating magnetic fields to provide information about the position of structures in motion (Joglar et al., 2009). The use of EMA has made it possible to revisit aspects of the kinematics of masticatory cycles that had before not been explored 
with any amount of accuracy. For example, today it is possible to individualize each masticatory cycle in order to describe and calculate its trajectory, to determine the area that each one occupies in the three spatial planes (frontal, sagittal and horizontal plane) (Fig.1), to measure the mandibular speed in each phase (opening or closing) and to quantify its frequency (Fuentes et al., 2017).

In terms of the morphology of the masticatory cycles, studies that use more modern techniques have corroborated the previous observations made with less accurate technologies, for example, that the cycles are elliptical with a great variation regarding amplitude, area, direction, inclination and side of preference in the frontal plane. Nevertheless, thanks to the studies conducted with EMA in 3D, today it is possible to also state that in the frontal plane cycles with a figure "8", with great irregularity in their trajectory and an inclination that can be vertical, horizontal or close to $45^{\circ}$ are described (Fig.1) (Fuentes et al., 2017).

It is now possible to study both the individualized cycles as well as the entire masticatory process in 3D, and concentric movements can even be differentiated from those eccentric ones made with the jaw (Fig. 2).

\section{MASTICATORY PERFORMANCE AND EFFICIENCY. At the same time} in which modern oral rehabilitation procedures have been developed, different methods have been proposed to measure or quantify masticatory function. In the beginning these methods lacked standardization and there was no consensus about which technique was best or what the test foods should be to assess mastication. However, the first reports agree in that the uses of natural food that is

\section{Plano Frontal}
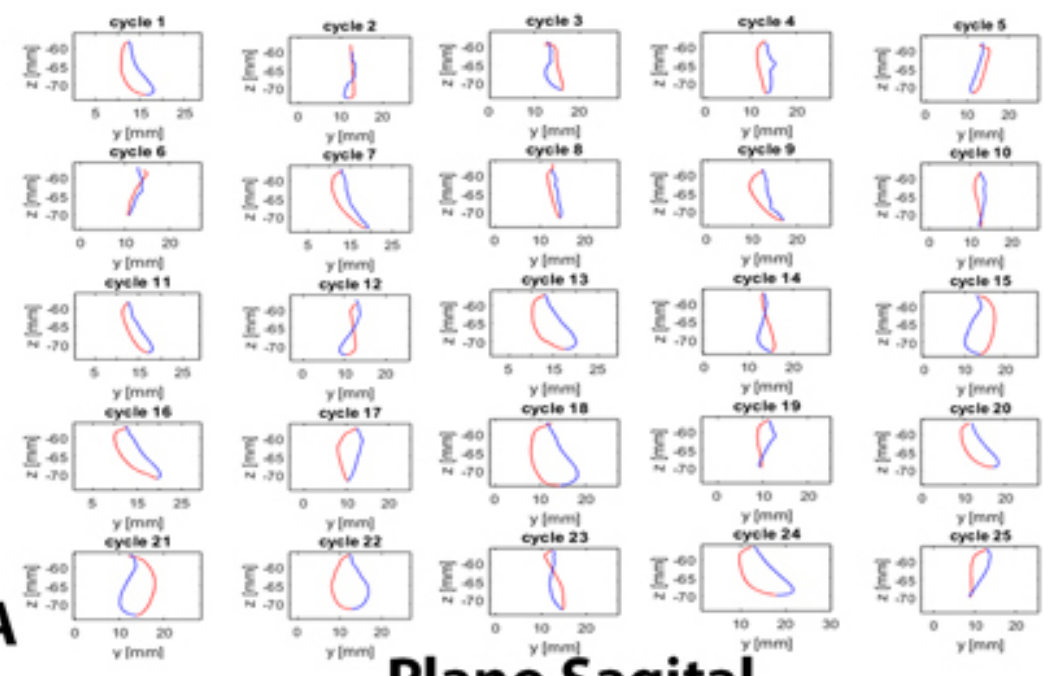

\section{Plano Sagital}
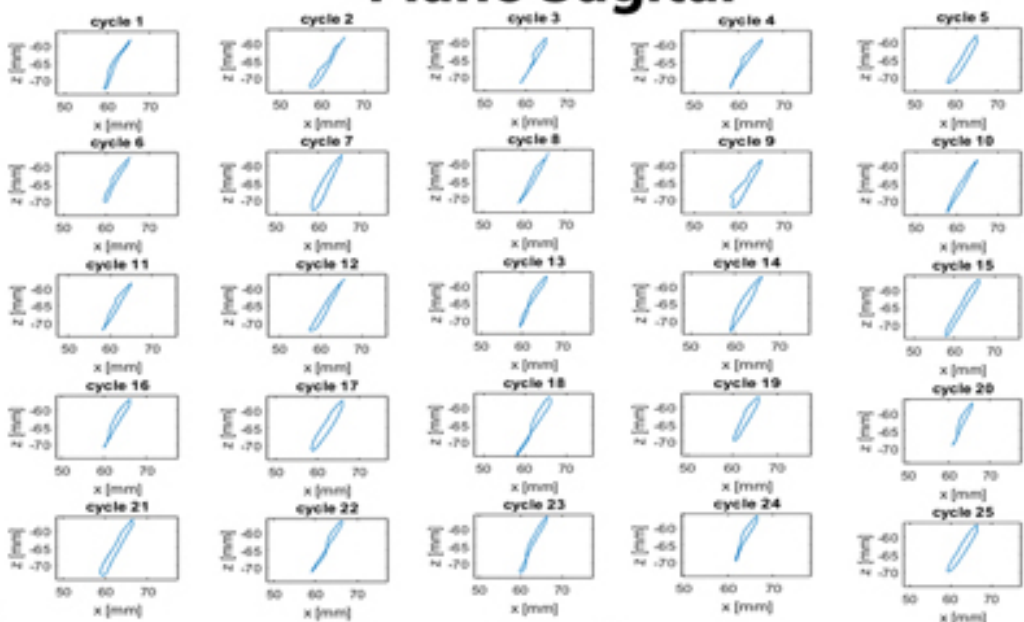

Plano Horizontal
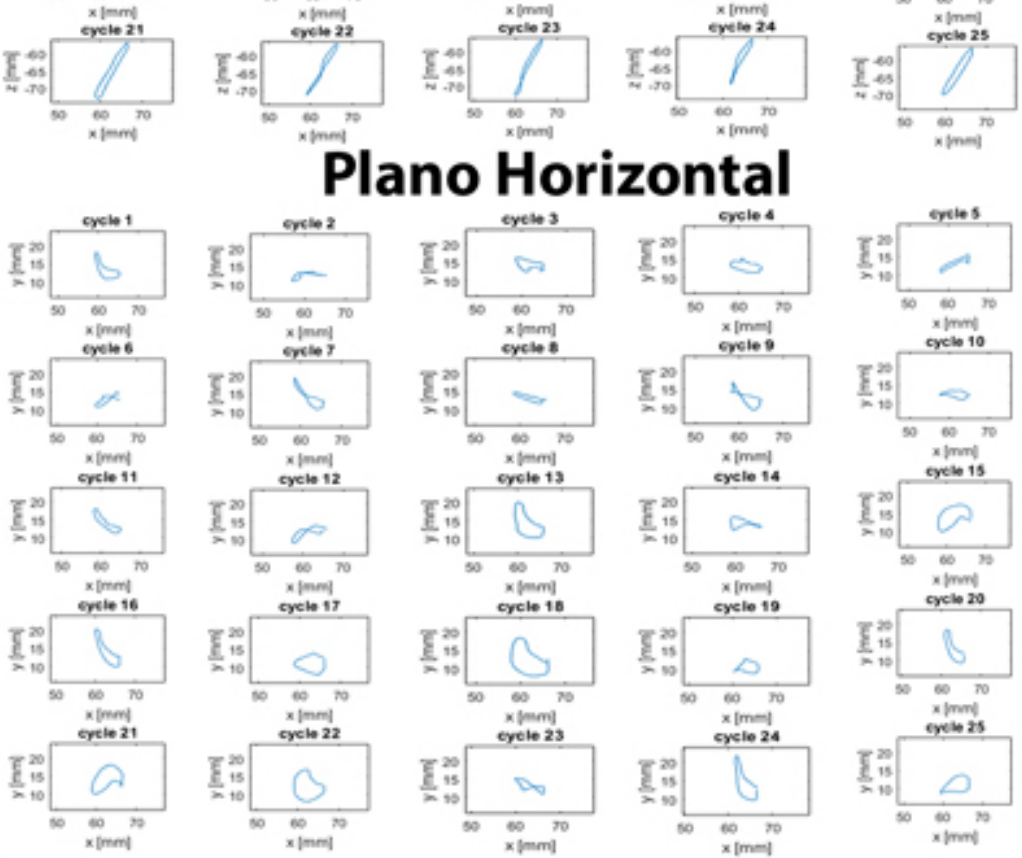

Fig. 1. Individualization of masticatory cycles through 3D electromagnetic articulography in:A: frontal plane, B:Sagittal plane, C:Horizontal plane. 


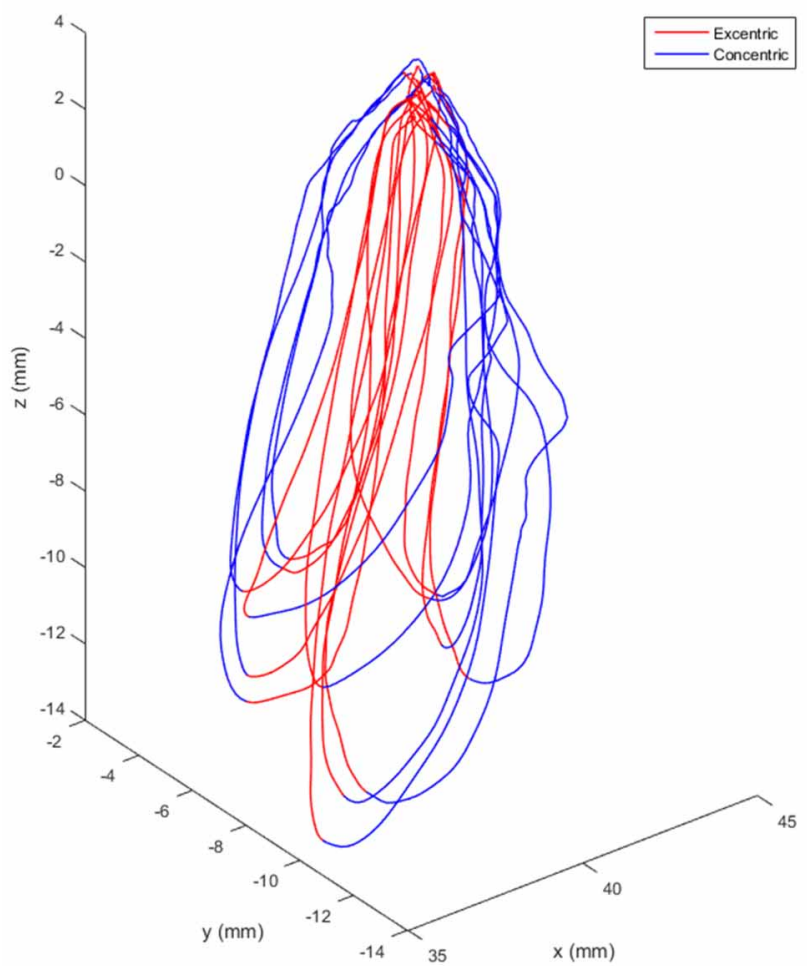

Fig. 2. Masticatory cycles observed on the $x-, y$, and z-axis, where the concentric (blue) and the eccentric (red) mandibular movement is differentiated.

usually consumed should be preferred, with peanut and its derivatives being a recurrent test food (Manly \& Bradley, 1950). Nowadays, a classic and widely used method for the evaluation of masticatory function is the determination of masticatory performance and efficiency proposed by Manly \& Bradley in 1950. According to that study, a person's masticatory performance can be calculated based on the percentage of peanut chewed which can pass through a sieve of a certain diameter (as a way to measure the degree of crushing of a food) executing a certain number of masticatory strokes or cycles (usually 20 masticatory strokes). In addition, masticatory efficiency can be calculated from the number of masticatory strokes or cycles required to obtain a certain level of pulverization of a food that is generally peanut (Manly \& Bradley). In this study it was determined that the masticatory performance of healthy subjects with complete natural teeth is $88 \%$, whereas efficiency is a parameter that varies substantially according to the number of teeth present (Manly \& Bradley).

Tooth loss and the consequent reduction in occlusal contacts is directly associated with a reduction in masticatory performance, mainly in older adults (Ikebe et al., 2012; Naka et al., 2014). Also, several exploratory population studies have found that people with better dentition and masticatory function report a significantly greater consumption of foods and ingestion of nutrients than those people with a reduced state of oral health (Tada \& Miura, 2014). A long tradition of published studies going back more than half a century has already indicated that masticatory performance is a determining factor for people when choosing what type of food to eat, seriously affecting nutrition, mainly of older adults (Buschang et al., 1997). More recent studies have investigated this aspect, finding that the state of dentition and the number of teeth present could influence food selection according to its texture (Ellis et al.), affecting the appropriate ingestion of certain foods such as fruits and vegetables (N'gom \& Woda, 2002).

On the other hand, tooth loss and the ensuing deterioration of the masticatory function have been negatively associated with the perception of oral healthrelated quality of life (Batista et al., 2014; Gerritsen et al., 2010) and with a greater incidence of symptoms of depression (Laudisio et al., 2014).

\section{CHEWING AND COGNITIVE FUNCTION}

In the last few years it has been seen that chewing not only fulfills a role in the processes of food ingestion and nutrition, but it is also able to influence the development of neurodegenerative diseases. One of the most relevant findings about chewing is that the cognitive function dependent on hippocampal activity may be closely related to masticatory function (Chen et al., 2015). This relation has begun to be studied more thoroughly since observational studies conducted on various adult populations have shown that low masticatory ability is associated with cognitive deterioration or dementia (Kim et al., 2017). Recent studies conducted on animal models have demonstrated that a reduction in masticatory activity results in a deterioration of spatial memory and learning function (FukushimaNakayama et al., 2017). In addition, studies on healthy subjects have shown that chewing can induce an activation of the right premotor cortex, precuneus, thalamus, hippocampus and inferior parietal lobe, which suggests its relation with positive effects on the memory (Hirano et al., 2008). The activation of different areas of the cerebral cortexresulting from chewing had already been previously proposed in studies where the mastication of chewing gum 
demonstrated an increase in regional blood flow of the brain in areas such as the primary sensorimotor area, complementary motor areas, insula, cerebellum and corpus striatum (Momose et al., 1997). Given that a deterioration in masticatory function is dependent on the presence of teeth, current studies suggest that the process of peripheral deafferentation in the stomatognathic system could project globally in the central nervous system and become a critical factor that could trigger and/or aggravate neurodegenerative diseases (Jou, 2018). A recent qualitative systematic review indicates that masticatory function can act as a protective factor in subjects with cognitive decline and neurodegenerative diseases by increasing cerebral blood flow. This may also be influenced by the intensity of the masticatory function and the number of functional teeth in the mouth (Chuhuaicura et al., 2019). Similarly, a greater number of residual teeth in an older adult also has been associated with a lower risk of suffering dementia later in life (Oh et al., 2018).

CHEWING AND QUALITY OF LIFE. Over time it has been possible to relate the increase in masticatory capacity with the increase in people's quality of life (Baba et al., 2009). Other factors, low education, being single and socioeconomic level have also been shown to reduce masticatory capacity in relation to the difficulty of chewing hard foods (Milagres et al., 2018). In relation to the number of teeth, completely edentulous subjects may not have seen an improvement in their quality of life after being treated with fully removable protheses (Alves et al., 2018), but there has been an increase associated with quality of life with the use of implants due to an increase masticatory efficiency and comfort (Sun et al., 2014).

\section{CONCLUSION}

Recent studies have offered a new vision of the mechanics of mastication and its impact on various processes such as nutrition or the development of neurodegenerative diseases. Thus, any modification in the state of dental health, salivary flow or neuromuscular apparatus can affect it.

It is necessary to stimulate chewing and for this purpose the choice of foods should consider the oral health status and chewing characteristics of each person. Therefore, it would be advisable for dentists to be integrated into the multidisciplinary nutrition team.

\section{ACKNOWLEDGEMENTS}

The authors wish to thank the Universidad Adventista de Chile for financial support through project $\mathrm{N}^{\circ}$ 2018-90.

FUENTES, R.; FARFÁN, C. \& ARIAS, A. Características de la masticación: Una actualización de la literatura. Int. J. Odontostomat., 15(4):873-881, 2021.

RESUMEN: La masticación es el primer paso en el proceso de digestión en los mamíferos, es un proceso altamente coordinado y con una compleja actividad sensoriomotora, cuyo objetivo es preparar los alimentos para la formación del bolo alimenticio y luego la deglución, es un proceso con etapas definidas y patrones de movimiento que se adaptan a los cambios derivados del entorno o del individuo, aquí se revisan las principales características de la masticación, incluyendo aspectos de la fisiología y características de la mecánica del movimiento mandibular, se destacan los últimos avances reportados y las nuevas metodologías utilizado para un análisis de la masticación, lo que ha permitido recolectar datos más precisos y confiables, así, veremos cómo las nuevas tecnologías han permitido comprender mejor esta función y su relación con aspectos de la salud general de un individuo como la nutrición o la aparición de enfermedades neurodegenerativas; además, en esta revisión destacamos la estrecha relación que existe entre la masticación y la calidad de vida.

PALABRAS CLAVE: masticación, ciclos de masticación, movimiento mandibular, nutrición, enfermedades neurodegenerativas, calidad de vida.

\section{REFERENCES}

Aguirre-Siancas, E. Bases neurocientíficas de la función masticatoria y su efecto sobre el estrés y las funciones cognitivas. Rev. Chil. Neuro-Psiquiat., 55(1):9-17, 2017.

Alves, A. C.; Cavalcanti, R. V.; Calderon, P. S.; Pernambuco, L. \& Alchieri. J. C. Quality of life related to complete denture. Acta Odontol. Latinoam., 31(2):91-6, 2018.

Avivi-Arber, L. \& Sessle, B. J. Jaw sensorimotor control in healthy adults and effects of ageing. J. Oral Rehabil., 45(1):50-80, 2018.

Baba, K.; John, M. T.; Inukai, M.; Aridome, K. \& Igarahsi, Y. Validating an alternate version of the chewing function questionnaire in partially dentate patients. BMC Oral Health, 9:9, 2009.

Batista, M. J.; Lawrence, H. P. \& Sousa, M. Impact of tooth loss related to number and position on oral health quality of life among adults. Health Qual Life Outcomes, 12:165, 2014.

Bourdiol, P.; Hennequin, M.; Peyron, M. A. \& Woda, A. Masticatory adaptation to occlusal changes. Front. Physiol., 11:263, 2020.

Buschang, P. H.; Throckmorton, G. S.; Travers, K. H. \& Johnson, G. The effects of bolus size and chewing rate on masticatory performance with artificial test foods. J. Oral Rehabil., 24(7):5226, 1997. 
Chen, H.; Linuma, M.; Onozuka, M. \& Kubo, K. Y. Chewing maintains hippocampus-deependent cognitive function. Int. J. Med. Sci., 12(6):502-9, 2015.

Cho, C.; Maawadh, A. \& Gerstner G. E. Comparisons of chewing rhythm, craniomandibular morphology, body mass and height between mothers and their biological daughters. Arch. Oral Biol., 60(11):1667-74, 2015.

Chuhuaicura, P.; Dias, FJ.; Arias, A.; Lezcano, MF.; Fuentes, R. Mastication as a protective factor of the cognitive decline in adults: A qualitative systematic review. Int. Dent. J., 69(5):33440, 2019.

Dellow, P. G. \& Lund, J. P. Evidence for central timing of rhythmical mastication. J. Physiol., 215(1):1-13. 1971.

Ellis, J. S.; Thomason, J. M.; Jepson, N. J.; Nohl, F.; Smith, D. G. \& Allen, P. F. A randomized-controlled trial of food choices made by edentulous adults. Clin. Oral Implants Res., 19(4):356-61, 2008.

Farfán, C.; Coaquira, J. J. Q.; Lezcano, M. F.; Arias, A.; Navarro, P. \& Fuentes, R. Análisis cinemático de la masticación de una granola prototipo en contraste con la masticación de maní. Int. J. Odontostomat., 14(2):198-204, 2020.

Flores-Orozco, E. I.; Rovira-Lastra, B.; Peraire, M.; Salsench, J. \& Martinez-Gomis, J. Reliability of a visual analog scale for determining the preferred mastication side. J. Prosthet. Dent., 115(2):203-8, 2016.

Fueki, K.; Yoshida, E. \& Igarashi, Y. Association between occlusal curvature and food comminution and mixing in human young adults with permanent dentitions. Arch. Oral Biol., 58(4):37783, 2013.

Fuentes, R.; Arias, A.; Lezcano, M. F.; Saravia, D.; Kuramochi, G. \& Dias, F. J. Systematic standardized and individualized assessment of masticatory cycles using electromagnetic 3D articulography and computer scripts. Biomed. Res. Int., 2017:7134389, 2017.

Fuentes, R.; Farfán, C.; Dias, F. J.; Arias, A. \& Lezcano, M. F. Analysis of mandibular movements and chewing cycles in patients with skeletal class III: A preliminary study. Transylv. Rev., 26(28), 2018a.

Fuentes, R.; Arias, A.; Lezcano, M. F.; Saravia, D.; Kuramochi, G., Navarro, P. \& Dias, F. J. A new tridimensional insight into geometric and kinematic characteristics of masticatory cycles in participants with normal occlusion. BioMed Res. Int., 2018:2527463, 2018b.

Fukushima-Nakayama, Y.; Ono, T.; Hayashi, M.; Inoue, M.; Wake, H.; Ono, T. \& Nakashima, T. Reduced mastication impairs memory function. J. Dent. Res., 96(9):1058-66, 2017.

Genaro, K. F.; Berretin-Felix, G.; Rehder, M. I. B. C. \& Marchesan, I. Q. Avaliação miofuncional orofacial: protocolo MBGR. Rev. CEFAC., 11(2):237-55, 2009.

Gerritsen, A. E.; Allen, P. F.; Witter, D. J.; Bronkhorst, E. M. \& Creugers, N. H. Tooth loss and oral health-related quality of life: a systematic review and meta-analysis. Health Qual Life Outcomes, 8:126, 2010.

Gonçalves, T. M., Vilanova, L. S., Gonçalves, L. M., \& Rodrigues Garcia, R. C. Effect of complete and partial removable dentures on chewing movements. J. Oral Rehabil., 41(3):177-83, 2014.

Hirano, Y.; Obata, T.; Kashikura, K.; Nonaka, H.; Tachibana, A.; Ikehira, H. \& Onozuka, M. Effects of chewing in working memory processing. Neurosci. Lett., 436(2):189-92, 2008.

Iguchi, H.; Magara, J.; Nakamura, Y.; Tsujimura, T.; Ito, K. \& Inoue, $M$. Changes in jaw muscle activity and the physical properties of foods with different textures during chewing behaviors. Physiol. Behav., 152(Pt A):217-24, 2015.

Ikebe, K.; Matsuda, K.; Kagawa, R.; Enoki, K.; Okada, T.; Yoshida, M. \& Maeda, Y. Masticatory performance in older subjects with varying degrees of tooth loss. J. Dent. 40(1):71-6, 2012.
Isabel, C. A.; Moysés, M. R.; van der Bilt, A.; Gameiro, G. H.; Ribeiro, J. C. \& Pereira, L. J. The relationship between masticatory and swallowing behaviors and body weight. Physiol. Behav., 151:3149, 2015.

Jiménez, A.; Pena, C.; Lee, X.; Vergara, C.; Tobar, J. \& Frugone, R. Patología temporomandibular asociada a masticación unilateral en adultos jóvenes. Rev. Clin. Periodoncia Implantol. Rehabil. Oral., 9(2):125-31, 2016.

Joglar, J. A.; Nguyen, C.; Garst, D. M. \& Katz, W. F. Safety of electromagnetic articulography in patients with pacemakers and implantable cardioverter-defibrillators. J. Speech Lang. Hear. Res., 52(4):1082-7, 2009.

Jou, Y. T. Dental deafferentation and brain damage: A review and a hypothesis. Kaohsiung J. Med. Sci., 34(4):231-37, 2018.

Kim, E. K.; Lee, S. K.; Choi, Y. H.; Tanaka, M.; Hirotsu, K.; Kim, H. C.; Lee, H. K.; Jung, Y. S. \& Amano, A. Relationship between chewing ability and cognitive impairment in the rural elderly. Arch. Gerontol. Geriatr., 70:209-213, 2017.

Kuninori, T.; Tomonari, H.; Uehara, S.; Kitashima, F.; Yagi, T. \& Miyawaki, S. Influence of maximum bite force on jaw movement during gummy jelly mastication. J. Oral Rehabil., 41(5):338-45, 2014.

Laudisio, A.; Milaneschi, Y.; Bandinelli, S.; Gemma, A.; Ferrucci, L. \& Incalzi, R. A. Chewing problems are associated with depression in the elderly: results from the InCHIANTI study. Int. J. Geriatr. Psychiatry., 29(3):236-44, 2014.

Lauzardo, G.; Muguercia, D.; Gutiérrez, M.; Áreas, O. \& Quintana, M. La sobredentadura, una opción válida en Estomatología. Rev. Cuba Estomatol., 40(3), 2013.

Lund, J. P. Mastication and its control by the brain stem. Crit. Rev. Oral Biol. Med., 2(1):33-64, 1991.

Lund, J. P., Kolta, A. Generation of the central masticatory pattern and its modification by sensory feedback. Dysphagia, 21(3):16774, 2006.

Manly, R. S. \& Bradley, L. C. Masticatory performance and efficiency. J. Dent. Res., 29(4):448-62, 1950.

Brizuela Cordero, C.; Biotti, P. J. L. \& Manns Freese, A. E. Sistema estomatognático: bases biológicas y correlaciones clínicas. En Sistema estomatognático: bases biológicas y correlaciones clínicas. Ripano, Editorial Médica, 2011. p. 433.

Milagres, C. S.; Tôrres, L.; Neri, A. L. \& Sousa, M. Condição de saúde buccal autopercebida, capacidade mastigatória e longevidade em idosos. Cien. Saude Colet., 23(5):1495-1506, 2018.

Mobley, C. \& Dounis, G. Dietary guidance for people wearing removable prostheses. J. Am. Dent. Assoc., 144(2):11-5, 2013.

Momose, T.; Nishikawa, J.; Watanabe, T.; Sasaki, Y.; Senda, M.; Kubota, K.; Sato, Y.; Funakoshi, M. \& Minakuchi, S. Effect of mastication on regional cerebral blood flow in humans examined by positron-emission tomography with $\partial$ ?O-labelled water and magnetic resonance imaging. Arch. Oral Biol., 42(1):57-61, 1997.

Morquette, P.; Lavoie, R.; Fhima, M. D.; Lamoureux, X.; Verdier, D. \& Kolta, A. Generation of the masticatory central pattern and its modulation by sensory feedback. Prog. Neurobiol., 96(3):34055,2012

Moya, M.; Marquardt, K. \& Olate, S. Caracterización de la función masticatoria en estudiantes universitarios. Int. J. Odontostomat., 11(4):495-9, 2017

N'gom, P. I. \& Woda, A. Influence of impaired mastication on nutrition. J. Prosthet. Dent., 87(6):667-73, 2002.

Naka, O.; Anastassiadou, V. \& Pissiotis, A. Association between functional tooth units and chewing ability in older adults: a systematic review. Gerodontology, 31(3):166-77, 2014.

Nicolas, E., Veyrune, J. L., Lassauzay, C., Peyron, M. A. \& Hennequin, M. Validation of video versus electromyography for chewing evaluation of the elderly wearing a complete denture. J. Oral. Rehabil., 34(8):566-71, 2007. 
Oh, B.; Han, D. H.; Han, K. T.; Liu, X.; Ukken, J.; Chang, C.; Dounis, K. \& Yoo, J. W. Association between residual teeth number in later life and incidence of dementia: A systematic review and meta-analysis. BMC Geriatrics, 18(1):48, 2018.

Ohkubo, C.; Kobayashi, M.; Suzuki, Y. \& Hosoi, T. Effect of implant support on distal-extension removable partial dentures: in vivo assessment. Int. J. Oral Maxillofac. Implants, 23(6):1095-101, 2008.

Rivera, P.; Farfán, C.; Arias, A.; Lezcano, M. F.; Dias, F. J.; Navarro, P. \& Fuentes, R. Characteristics of mandibular movement and mastication in older adults with removable dental prostheses: Three-dimensional analysis. Int. J. Odontostomat., 14(1):81-8, 2020.

Rosado De Oliveira, J.S.; Mattoso, F. C. P.; Costa De Oliveira, A. B. \& Dininno, C. Q. M. S. Fonoaudiologia e adaptação de prótese dentária total em idosos: o que os dentistas sabem sobre isto? Rev. Speech, Lang. Hear. Sci. Educ. J., 7(1):50-4, 2005.

Saez Carriera, R.; Carmona, M.; Jimenez Quintana, Z. \& Alfaro, X. Cambios bucales en el adulto mayor. Rev. Cuba Estomatol., 44(4):1-14, 2007.

Soboleva, U.; Laurina, L. \& Slaidina, A. The masticatory system - an overview. Stomatologija, 7(3):77-80, 2005.

Sun, X.; Zhai, J. J.; Liao, J.; Teng, M. H.; Tian, A. \& Liang, X. Masticatory efficiency and oral health-related quality of life with implant-retained mandibular overdentures. Saudi Med. J., 35(10):1195-202, 2014.

Tada, A. \& Miura, H. Systematic review of the association of mastication with food and nutrient intake in the independent elderly. Arch. Gerontol. Geriatr., 59(3):497-505, 2014.

Toman, M.; Toksavul, S.; Saracoglu, A.; Cura, C.; Hatipoglu, A. Masticatory performance and mandibular movement patterns of patients with natural dentitions, complete dentures, and implantsupported overdentures. Int. J. Prosthodont., 25(2):135-7, 2012.

van der Bilt, A.; Weijnen, F. G.; Ottenhoff, F. A. M.; van der Glas, H. W. \& Bosman, F. The role of sensory information in the control of rhythmic open-close movements in humans. J. Dent. Res. 74:1658-64, 1995.

Van der Laan, T. Função mastigatória em índios lanomami. Tese Mestrado em Ciências. Piracicaba, Universidade Estadual de Campinas, 1998.

Woda, A.; Foster, k.; Mishellany, A.; Peyron, M. A. Adaptation of healthy mastication to factors pertaining to the individual or to the food. Physiol. Behav., 89(1):28-35, 2006.

Yoshida, E.; Fueki, K. \& Igarashi, Y. Association between food mixing ability and mandibular movements during chewing of a wax cube. J. Oral Rehabil., 34(11):791-9, 2007.

Yoshida, T.; Ishikawa, H.; Yoshida, N. \& Hisanaga, Y. Analysis of masseter muscle oxygenation and mandibular movement during experimental gum chewing with different hardness. Acta Odontol. Scand., 67(2):113-21, 2009.
Corresponding author

Dr. Ramón Fuentes Fernández

Centro de Investigación en Ciencias Odontológicas (CICO)

Facultad de Odontología

Universidad de La Frontera

Av. Francisco Salazar 1145

Temuco

CHILE

E-mail: ramon.fuentes@ufrontera.cl 